\title{
Terrestrial Ecosystem Ecology Principles and Applications
}

Goran I. Agren and Folke O. Andersson. 2012. ISBN 978-1-107-64825-8 Cambridge University Press, New York, NY. US \$ 59.00 (paperback) + shipping. Contact: publicity@cambridge.org

I uman activities impact the environI ment and modify the cycles of important elements such as carbon and nitrogen from local to global scales. In order to maintain long-term and sustainable use of the world's natural resources, it is important that we understand how and why ecosystems respond to such changes.

This book explains the structure and functioning of terrestrial ecosystems, using examples ranging from the Artic to the Tropics to demonstrate how they react under differing conditions. This knowledge is developed into a set of principles that can be used as starting points for analyzing questions about ecosystem behavior. Ecosystem dynamics are also considered, illustrating how ecosystems develop and change over a range of temporal and spatial scales, and how they react to perturbations, whether natural or man-made. Throughout the book, descriptive studies are merged with simple mathematical models to enforce the concepts discussed and aid the development of predictive tools.

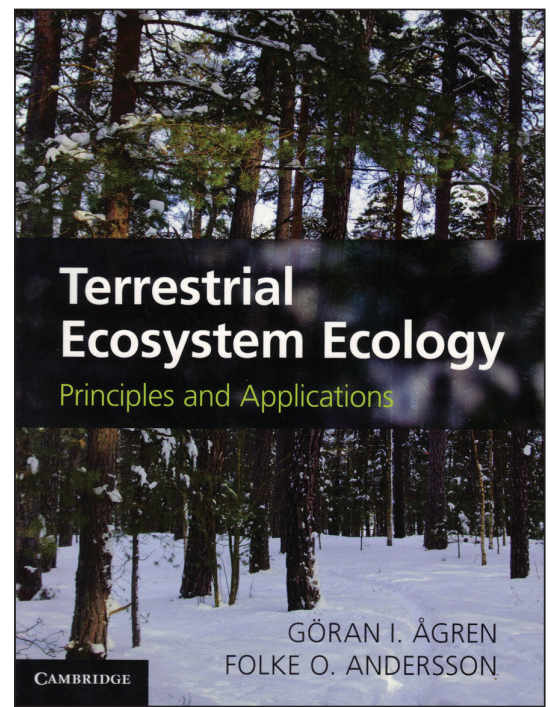

\section{Empire of the Beetle - How Human Folly and a Tiny Bug are Killing North America's Great Forests}

Andrew Nikiforuk. 2011. ISBN 978-1-555365-510-7 Greystone Books, Vancouver \$US $17.95+$ shipping. 230 pp.

mpire of the Beetle chronicles the $\boldsymbol{E}$ devastating bark beetle outbreaks that have impacted portions of Western North America, beginning in the 1980s, and how a series of human errors have allegedly set the stage for the wake of destruction they have caused. Calgary-based Rachel Carson Environment Book Award winner Andrew Nikiforuk details a massive outbreak of spruce beetle, Dendroctonus rufipennis, that occurred in Alaska during the 1980s and 90s, outbreaks of mountain pine beetle, $D$. ponderosae, in British Columbia, Alberta and the western USA, beginning about 1996, and an outbreak of pinyon ips, Ips confusus, that devastated pinyon pine forests in the American Southwest from 2002-2005.
The book is organized into 10 chapters that describe the outbreaks, the biology and ecology of bark beetles, research underway to achieve a better understanding of bark beetles and their interactions with forests and attempts to manage the outbreaks. Also included is a chapter on the natural history of beetles, the most abundant order of insects. Bark beetles are likened to a "bus" that carries an assortment of fungi, mites and bacteria into trees. Trees are referred to as "castles" and a tree susceptible to attack is a "castle without hot oil". He argues that the key factors responsible for the current wave of massive outbreaks is climate change and, in the case of mountain pine beetle, fire exclusion. He further argues that human efforts to combat these out-

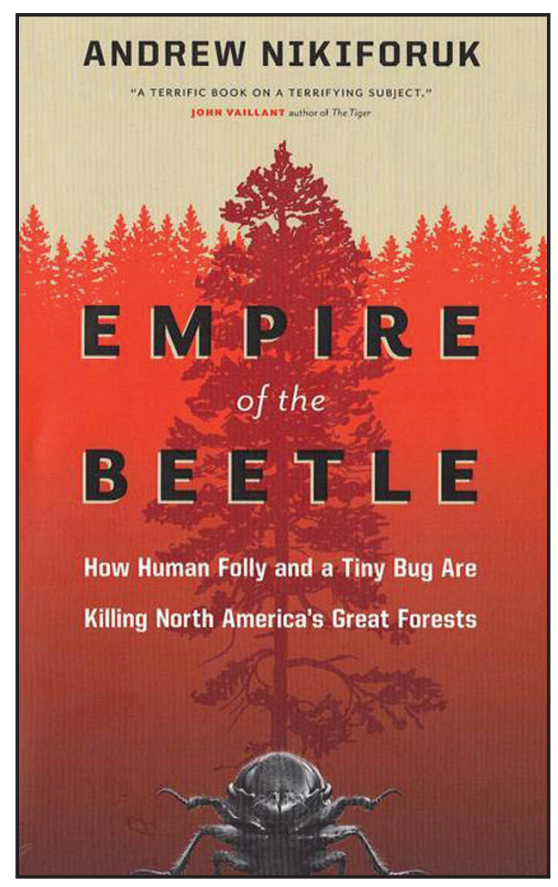

breaks have been an exercise in futility and that extensive salvage logging and road construction in beetle-infested areas by forest industry has reduced the biodiversity of the affected ecosystems. 